\title{
Antimicrobial Resistance Profiling of Biofilm Forming Non Typhoidal Salmonella enterica Isolates from Poultry and Its Associated Food Products from Pakistan
}

\author{
Abubakar Siddique ${ }^{1}$, Sara Azim ${ }^{1}$, Amjad Ali ${ }^{1}$ (D), Saadia Andleeb ${ }^{1}$, Aitezaz Ahsan ${ }^{2}$, Muhammad Imran ${ }^{3}$ and \\ Abdur Rahman $1, *$ (D) \\ 1 Atta Ur Rahman School of Applied Biosciences (ASAB), National University of Sciences and \\ Technology (NUST), H-12, Islamabad 44000, Pakistan; mabubakar.asab@asab.nust.edu.pk (A.S.); \\ saraazim94@gmail.com (S.A.); amjad.ali@asab.nust.edu.pk (A.A.); saadia.andleeb@asab.nust.edu.pk (S.A.) \\ 2 Animal Health Program, Animal Sciences Institute, National Agriculture Research Centre, Park Road, \\ Islamabad 44000, Pakistan; draitzaz786@gmail.com \\ 3 Department of Biosciences, Faculty of Sciences, COMSATS University Islamabad, Park Road, \\ Islamabad 44000, Pakistan; m.imran@comsats.edu.pk \\ * Correspondence: a.rahman@asab.nust.edu.pk
}

check for updates

Citation: Siddique, A.; Azim, S.; Ali, A.; Andleeb, S.; Ahsan, A.; Imran, M.; Rahman, A. Antimicrobial Resistance Profiling of Biofilm Forming Non Typhoidal Salmonella enterica Isolates from Poultry and Its Associated Food Products from Pakistan. Antibiotics 2021, 10, 785. https://doi.org/ 10.3390/antibiotics10070785

Academic Editors: Carlos Manuel Franco and Susana Ferreira

Received: 19 March 2021

Accepted: 25 May 2021

Published: 28 June 2021

Publisher's Note: MDPI stays neutral with regard to jurisdictional claims in published maps and institutional affiliations.

Copyright: (c) 2021 by the authors. Licensee MDPI, Basel, Switzerland. This article is an open access article distributed under the terms and conditions of the Creative Commons Attribution (CC BY) license (https:/ / creativecommons.org/licenses/by/ $4.0 /)$.

\begin{abstract}
Salmonellosis caused by non-typhoidal Salmonella enterica from poultry products is a major public health concern worldwide. This study aimed at estimating the pathogenicity and antimicrobial resistance in S. enterica isolates obtained from poultry birds and their food products from different areas of Pakistan. In total, 95/370 (25.67\%) samples from poultry droppings, organs, eggs, and meat were positive for Salmonella. The isolates were further identified through multiplex PCR (mPCR) as Salmonella Typhimurium 14 (14.7\%), Salmonella Enteritidis 12 (12.6\%), and other Salmonella spp. 69 (72.6\%). The phenotypic virulence properties of 95 Salmonella isolates exhibited swimming and/or swarming motility 95 (100\%), DNA degrading activity 93 (97.8\%), hemolytic activity $92(96.8 \%)$, lipase activity 87 (91.6\%), and protease activity 86 (90.5\%). The sopE virulence gene known for conferring zoonotic potential was detected in S. Typhimurium (92.8\%), S. Enteritidis (100\%), and other Salmonella spp. (69.5\%). The isolates were further tested against 23 antibiotics (from 10 different antimicrobial groups) and were found resistant against fifteen to twenty-one antibiotics. All isolates showed multiple drug resistance and were found to exhibit a high multiple antibiotic-resistant (MAR) index of 0.62 to 0.91 . The strong biofilm formation at $37^{\circ} \mathrm{C}$ reflected their potential adherence to intestinal surfaces. There was a significant correlation between antimicrobial resistance and the biofilm formation potential of isolates. The resistance determinant genes found among the isolated strains were $b l a_{T E M-1}(59.3 \%)$, bla $_{O x A-1}(18 \%)$, bla $a_{P S-1}(9.5 \%), b l a_{C M Y-2}(43 \%)$, and ampC $(8.3 \%)$. The detection of zoonotic potential MDR Salmonella in poultry and its associated food products carrying cephalosporin and quinolone resistance genes presents a major threat to the poultry industry and public health.
\end{abstract}

Keywords: poultry; Salmonella enterica; NTS; eggs; antibiotic resistance; MAR index; Pakistan

\section{Introduction}

Non-typhoidal Salmonella (NTS) is one of the most important zoonotic foodborne pathogens [1] globallyGharieb, Tartor. About 2600 serovars of Salmonella enterica have been reported, which can cause disease in both animals and humans [2,3]. Gastroenteritis is the most common Salmonella infection in humans, accounting for 94 million cases each year, where 80.3 million are related to foodborne illnesses [4,5]. Major Salmonella outbreaks are caused by consuming contaminated poultry food (meat and eggs). At the same time, poultry farm handlers are also at risk due to direct or indirect contact with poultry birds [6,7]. Biofilm formation is important for the spread of NTS because biofilm-forming bacteria are resistant to drugs, disinfectants, and mechanical stress, making these biofilms 
a safety risk for the food industry. A variety of virulence factors and biofilm formation potential play an important role in the pathogenesis of Salmonella infection [8]. The irrational use of antibiotics in animal husbandry results in ever-increasing antimicrobial resistance in pathogens, including Salmonella enterica. Multidrug-resistant (MDR) and extended drug-resistant (XDR) Salmonella causes a serious threat to humans via transmission through the food chain [9]. Therefore, it is mandatory to monitor the antibiotic resistance patterns of Salmonella enterica in the food chain. Currently, third- and fourth-generation cephalosporin and fluoroquinolones are widely used to treat salmonellosis in humans and animals. However, the emergence of bacterial resistance to these clinically important antibiotics needs to be monitored [10-12]. In the Enterobacteriaceae family, resistance to cephalosporins is mainly linked with the production of large spectrum beta-lactamases such as ESBL (extended-spectrum beta-lactamases) and AmpC beta-lactamase [13]. Quinolone resistance is mainly associated with the mutations in quinolone resistance determining regions (QRDR) of gyrA, gyrB, parC, and parE. Extended-spectrum cephalosporin and fluoroquinolone-resistant Salmonella serovars have been isolated from food-producing animals and their products in many countries [14].

In Pakistan, there are very few reports regarding the pathogenicity and antimicrobial susceptibility pattern of Salmonella serovars from poultry farms. In addition, such studies were have been limited to one geographical region and targeted limited serovars for antimicrobial resistance. Therefore, it necessitates the surveillance of antibiotic resistance and biofilm potential and virulent characteristics of $S$. enterica serovars from poultry gut and poultry food from major cities across Pakistan. This study is the first report to the best of our knowledge which is based on samples from four major regions (Punjab, Sindh, Khyber Pakhtunkhwa (KPK), and Islamabad (Capital Territory) of Pakistan, where extensive commercial poultry farming is practiced. This study aimed to investigate the incidence, molecular detection of Salmonella enterica serovars, antibiotic resistance pattern, virulence factors, and biofilm potential of Salmonella isolated from poultry droppings, organs, and poultry products from commercial poultry farms and retail markets.

\section{Material and Methods}

\subsection{Sample Collection}

Salmonella enterica isolates were isolated from poultry droppings and poultry products, as previously described [14]. A total of 370 samples were collected between 2017 and 2018 from different commercial poultry farms and retail markets from various cities in Punjab, Sindh, KPK, and Islamabad (Capital Territory) of Pakistan. The samples were collected from birds indicating Salmonella infection symptoms, as confirmed by the farm resident veterinarian. Among 370 samples, 180 were from fresh droppings, 70 from poultry organs (liver, spleen, intestine, and ovary), and 60 samples each from meat and eggs. Sterile swabs were used for sampling from eggs and fresh feces, while $10 \mathrm{~g}$ meat and organs were collected aseptically. Samples were stored at $4{ }^{\circ} \mathrm{C}$ and transported to the lab for subsequent isolation.

\subsection{Isolation of Salmonella Isolates}

Fecal and egg samples were washed with $0.5 \mathrm{~mL}$ phosphate buffer saline (PBS), and $0.1 \mathrm{~mL}$ of them was inoculated in selective enrichment broth Selenite F broth (HIMEDIA, IND) and incubated at $37^{\circ} \mathrm{C}$ for $24 \mathrm{~h}$. For meat and organ samples, $1 \mathrm{~g}$ of each sample was mixed with $5 \mathrm{~mL}$ PBS and homogenized using pestle and mortar, and $1 \mathrm{~mL}$ of homogenized sample was mixed with $9 \mathrm{~mL}$ Selenite $\mathrm{F}$ broth and incubated at $37^{\circ} \mathrm{C}$ for $24 \mathrm{~h}$. After selective enrichment was completed, a serial dilution of each sample was made up to $10^{-8} .100 \mu \mathrm{L}$ of enriched samples were spread on Salmonella Shigella (SS) agar (Oxoid, UK) plates and incubated at $37{ }^{\circ} \mathrm{C}$ for $24 \mathrm{~h}$. Two or three suspected Salmonella black colonies on agar plates were picked to obtain purified isolates by further streaking method. Biochemical tests including Triple Sugar Iron (TSI), Citrate utilization, Urease, Sulphate, Indole, and motility tests were performed for preliminary screening of Salmonella enterica 
identification [15]. Overnight grown bacterial cultures were streaked on Triple Sugar Iron agar (Oxoid, UK.) Simmons Citrate agar (Oxoid, UK), Urease agar (Oxoid, UK), and Sulphate, Indole Motility (SIM) agar (HIMEDIA, IND) and were incubated at $37^{\circ} \mathrm{C}$ for $24 \mathrm{~h}$ for subsequent biochemical characterization.

\subsection{Molecular Detection of Salmonella using Multiplex PCR}

The identified isolates were cultivated in Luria broth LB (Merck, Germany) and incubated at $37^{\circ} \mathrm{C}$ for $24 \mathrm{~h}$. Bacterial DNA was extracted using a DNA extraction kit (GF-1 Bacterial DNA Extraction Kit, Vivantis, Malaysia) according to the manufacturer's instructions. For serovar identification, a multiplex PCR was performed. ST11-ST15 primers were selected from a randomly cloned gene and were specific to Salmonella enterica. Sef167-Sef478 primers were chosen from the sefA gene and were specific to $S$. Enteritidis. Fli15-Tym primers were selected from the fliC gene and were specific to $S$. Typhimurium. All primers for these genes were purchased from (Eurofins Scientific, France) (Table 1). The PCR reaction was carried out for initial denaturing at $94{ }^{\circ} \mathrm{C}$ for $5 \mathrm{~min}, 35$ cycles of $94{ }^{\circ} \mathrm{C}$ for $30 \mathrm{~s}, 56^{\circ} \mathrm{C}$ for $1 \mathrm{~min} 30 \mathrm{~s}$ and $72{ }^{\circ} \mathrm{C}$ for $30 \mathrm{~s}$, followed by a final extension at $72{ }^{\circ} \mathrm{C}$ for $10 \mathrm{~min}$ [16]. Amplified PCR products were separated by electrophoresis on $1.5 \%$ agarose gel (bio-WORLD, USA). The gel was visualized under UV light, and images were analyzed with the Bio-Rad Gel Doc 1000 imager system.

Table 1. Primers used for Salmonella detection with Multiplex PCR.

\begin{tabular}{|c|c|c|c|c|c|c|}
\hline $\begin{array}{c}\text { Target } \\
\text { Sequence }\end{array}$ & $\begin{array}{l}\text { Target } \\
\text { Strain }\end{array}$ & Primer Sets & Length & $\begin{array}{c}\text { Primer Sequence } \\
5^{\prime}-3^{\prime}\end{array}$ & $\begin{array}{l}\text { Amplification } \\
\text { Region }\end{array}$ & Reference \\
\hline \multirow{2}{*}{$\begin{array}{l}\text { Random } \\
\text { Sequence }\end{array}$} & \multirow{2}{*}{ Salmonella spp. } & ST11 & 24 & GCCAACCATTGCTAAATTGGCGCA & \multirow{2}{*}{429} & \multirow{2}{*}{ [17] } \\
\hline & & ST15 & 24 & GGTAGAAATTCCCAGCGGGTACTGG & & \\
\hline \multirow{2}{*}{ fliC gene } & Salmonella & Fli15 & 22 & CGGTGTTGCCCAGGTTGGTAAT & \multirow{2}{*}{559} & \multirow{2}{*}{ [17] } \\
\hline & Typhimurium & Tym & 22 & ACTCTTGCTGGCGGTGCGACTT & & \\
\hline \multirow{2}{*}{ sefA gene } & Salmonella & Sef 167 & 20 & AGGTTCAGGCAGCGGTTACT & \multirow{2}{*}{312} & \multirow{2}{*}{ [17] } \\
\hline & Enteritidis & Sef 478 & 20 & GGGACATTTAGCGTTTCTTG & & \\
\hline
\end{tabular}

\subsection{Antimicrobial Susceptibility Assay}

The antimicrobial susceptibility of Salmonella isolates was performed according to the Kirby-Bauer Disk Diffusion method as previously described [3]. Twenty-three antibiotics were selected based on clinical relevance, veterinary and poultry farm practices, which belong to different antimicrobial groups. The antibiotic discs (Oxoid, UK) used were as follows; amikacin $(30 \mu \mathrm{g})$, chloramphenicol $(30 \mu \mathrm{g})$, tetracycline $(30 \mu \mathrm{g})$, cefixime $(5 \mu \mathrm{g})$, amoxicillin/clavulanic acid $(10 \mu \mathrm{g})$, ciprofloxacin $(10 \mu \mathrm{g})$, gentamicin $(30 \mu \mathrm{g})$, nalidixic acid $(30 \mu \mathrm{g})$, cefepime $(30 \mu \mathrm{g})$, trimethoprim/sulfamethoxazole $(25 \mu \mathrm{g})$, ampicillin $(30 \mu \mathrm{g})$, imipenem $(10 \mu \mathrm{g})$, meropenem $(10 \mu \mathrm{g})$, vancomycin $(30 \mu \mathrm{g})$, streptomycin $(25 \mu \mathrm{g})$, erythromycin $(30 \mu \mathrm{g})$, linezolid $(30 \mu \mathrm{g})$, rifampicin $(30 \mu \mathrm{g})$, enrofloxacin $(30 \mu \mathrm{g})$, oxacillin $(5 \mu \mathrm{g})$, clindamycin $(10 \mu \mathrm{g})$, minocycline $(30 \mu \mathrm{g})$, and kanamycin $(30 \mu \mathrm{g})$. Salmonella isolates were grown on Luria broth (LB) (Oxoid, UK) at $37^{\circ} \mathrm{C}$ for $18 \mathrm{~h} .100 \mu \mathrm{L}$ of each overnight grown bacterial isolate was spread on 6-inch Muller-Hinton agar (MH) (Oxoid, UK) plates, antibiotic discs were placed on the agar plates and incubated at $37^{\circ} \mathrm{C}$ for $18 \mathrm{~h}$. Zones of inhibition were measured and interpreted by comparing with the breakpoints established for each antimicrobial according to the guidelines by the Clinical and Laboratory Standards Institute (CLSI 2017). Any isolate which has acquired non-susceptibility to at least one agent in three or more antimicrobial categories is considered multi-drug-resistant (MDR). The multiple antibiotic resistance index (MAR) was calculated as:

MAR index $=$ No. of antibiotics resistant/No. of antibiotics tested 


\subsection{Molecular Detection of Antibiotic Resistance and Virulence Genes}

Major antibiotic resistance genes in Salmonella isolates were identified using multiplex PCR. Different groups of antibiotics were selected, including beta-lactam, cephalosporins, and carbapenems (bla CMY-2, blaOXA-1, bla PSE-1, bla TEM-1, bla NDM-1, and ampC), and the zoonotic potential virulence gene sopE was targeted. The primer sequences and annealing temperature conditions were showed (Table 2). PCR conditions (except annealing temperature) of all target genes were: initial denaturation at $94{ }^{\circ} \mathrm{C}$ for $5 \mathrm{~min}$ followed by 30 cycles of denaturation at $94^{\circ} \mathrm{C}$ for $30 \mathrm{~s}$, primer annealing at a specific temperature for $45 \mathrm{~s}$ and extension at $72{ }^{\circ} \mathrm{C}$ for $30 \mathrm{~s}$. The final extension step was done at $72{ }^{\circ} \mathrm{C}$ for $8 \mathrm{~min}$ [17].

Table 2. Primers and PCR conditions used for antibiotic resistance genes and virulence factor detection.

\begin{tabular}{|c|c|c|c|c|}
\hline Genes & Sequences $\left(5^{\prime}-3^{\prime}\right)$ & Annealing Temp. $\left({ }^{\circ} \mathrm{C}\right)$ & Amplicon Size & References \\
\hline bla PSE-1 & $\begin{array}{l}\text { CGCTTCCCGTTAACAAGTAC } \\
\text { CTGGTTCATTTCAGATAGCG }\end{array}$ & 50 & 430 & [18] \\
\hline bla $C M Y-2$ & $\begin{array}{c}\text { TGGCCAGAACTGACAGGCAAA } \\
\text { TTTCTCCTGAACGTGGCTGGC }\end{array}$ & 57 & 870 & \\
\hline bla TEM-1 & $\begin{array}{l}\text { CAGCGGTAAGATCCT TGAGA } \\
\text { ACTCGCCGTCGTGTAGATAA }\end{array}$ & 55 & 643 & [19] \\
\hline bla $O x A-1$ & $\begin{array}{c}\text { ATGAAAAACACAATACATATC } \\
\text { AATTTAGTGTGTTTAGAATGG }\end{array}$ & 50 & 830 & \\
\hline bla NDM-1 & $\begin{array}{l}\text { GGG CAG TCG CTT CCA ACG GT } \\
\text { GTA GTG CTC AGT GTC GGC AT }\end{array}$ & 58 & 475 & [20] \\
\hline $\operatorname{ampC}$ & $\begin{array}{c}\text { AACACACTGATTGCGTCTGAC } \\
\text { CTGGGCCTCATCGTCAGTTA }\end{array}$ & 60 & 1226 & [9] \\
\hline SopE & $\begin{array}{l}\text { ACACACTTTCCACGAGGAAGCG } \\
\text { GGATGCCTTCTGATGTTGACTGG }\end{array}$ & 50 & 398 & [21] \\
\hline
\end{tabular}

\subsection{Biofilm Characterization of Salmonella Isolates}

The biofilm-forming potential of Salmonella isolates was determined by using a 96 well microtiter plate method as described previously [22], with slight modifications. Twohundred microliters of Tryptic Soy Broth (TSB) and $20 \mu \mathrm{L}$ overnight grown Salmonella culture was poured into 96 well microtiter plate. Plates were incubated at $30^{\circ} \mathrm{C}$ and $37^{\circ} \mathrm{C}$ separately for $48 \mathrm{~h}$. Each well was washed twice with sterile phosphate-buffered saline (PBS) to remove planktonic cells. The remaining cells were fixed with $200 \mu \mathrm{L}$ of methanol for $15 \mathrm{~min}$. Wells were allowed to air dry and stained with $200 \mu \mathrm{L}$ of $2 \%$ crystal violet for $30 \mathrm{~min}$. The wells were carefully washed with distilled water to remove the excess stain. Plates were allowed to dry at room temperature. Dye bound to adherent cells were solubilized with $150 \mu \mathrm{L}$ of $30 \%$ acetic acid. $30 \%$ acetic acid was taken as a negative control. A microplate reader (Bio-rad, USA) was used to read the plates at $620 \mathrm{~nm}$ wavelength. Three standard deviations above the mean OD of the negative control for the microtiter plate test were defined as the cut-off optical density $(\mathrm{ODc})$. Isolates were classified as follows: $\left(4 \times \mathrm{OD}_{\mathrm{C}}\right)<\mathrm{OD}=$ strongly adherent, $\left(2 \times \mathrm{OD}_{\mathrm{C}}\right)<\mathrm{OD} \leq\left(4 \times \mathrm{OD}_{\mathrm{C}}\right)=$ moderately adherent, $\mathrm{OD}_{\mathrm{C}}<\mathrm{OD} \leq\left(2 \times \mathrm{OD}_{\mathrm{C}}\right)=$ weakly adherent, and $\mathrm{OD} \leq \mathrm{OD}_{\mathrm{C}}=$ non-adherent [23].

\subsection{Phenotypic Characterization of Extracellular Virulence Factors in Salmonella Isolates}

Salmonella isolates were grown in tryptic soy broth (Oxoid, UK) and incubated at $37^{\circ} \mathrm{C}$ for $24 \mathrm{~h}$. For hemolytic activity, $100 \mathrm{uL}, 0.5 \mathrm{McF}$ arland bacterial suspensions were streaked on blood agar plates supplemented with 7\% sheep blood and incubated for $24-48 \mathrm{~h}$ at $37^{\circ} \mathrm{C}$. Plates were observed for the formation of any clean ( $\alpha$-hemolysis) or greenish ( $\beta$ hemolysis) hemolytic zones or no zone ( $\gamma$-hemolysis). For lipase activity, $100 \mu \mathrm{L}$ bacterial culture was streaked on tryptic soy agar supplemented with tween 80 and incubated for $24-48 \mathrm{~h}$ at $37^{\circ} \mathrm{C}$. Clear halo zones around bacterial colonies were taken as positive. For protease activity, $100 \mu \mathrm{L}$ inoculum was poured on TSA plates supplemented with $1 \%$ casein 
from bovine milk (Sigma Aldrich, Germany) and incubated for $24-48 \mathrm{~h}$ at $37^{\circ} \mathrm{C}$. A clear zone because of casein hydrolysis was considered a positive result. For DNA degrading activity, $100 \mu \mathrm{L}$ bacterial suspension was inoculated on DNase agar (Oxoid, UK). Plates were incubated for $24-48 \mathrm{~h}$ at $37^{\circ} \mathrm{C}$. The clear zone around colonies was considered positive for DNase activity [24].

\subsection{Statistical Analysis}

Spearman's correlations between the number of MDR isolates and their biofilm formation were analyzed using SPSS version 20.0 software (IBM Corporation, Armonk, NY, USA).

\section{Results}

\subsection{Prevalence and Isolation of Salmonella Enterica Serovars}

Among 370 samples, $26.7 \%$ (48/180) from poultry feces, $24.3 \%$ (17/70) from poultry organs, and $25 \%(30 / 120)$ from poultry meat and eggs were positive for Salmonella (Table 3). Colorless colonies with black center on SS agar plates were observed. The biochemical reactions on TSI agar slants were typical of Salmonella (alkaline slant and acidic butt and produce $\mathrm{H}_{2} \mathrm{~S}$ ). All 95 isolates were citrate and sulfate positive and negative for urease and indole tests, respectively. All Salmonella isolates exhibited swimming and swarming motility. Multiplex PCR of 95 isolates differentiated them into various Salmonella enterica serovars: Salmonella Enteritidis (12/95) 12.6\%, Salmonella Typhimurium (14/95) $14.7 \%$, and other Salmonella spp. (69/95) 72.6\% (Table 3).

Table 3. Prevalence of Salmonella in poultry feces, poultry organs, and poultry food products.

\begin{tabular}{|c|c|c|c|c|c|}
\hline Sr. No. & Sample Source & $\begin{array}{l}\text { No. of Samples } \\
(n)\end{array}$ & $\begin{array}{c}\text { Positive Samples } \\
\text { (\%) }\end{array}$ & Serovar (s) Isolated & $\begin{array}{l}\text { No. of Serovar out of } \\
\text { Positive Sample (\%) }\end{array}$ \\
\hline \multirow{4}{*}{1} & \multirow{4}{*}{ Poultry feces } & \multirow{4}{*}{180} & \multirow{3}{*}{$48(26.7)$} & S.Typhimurium & $9(18.75)$ \\
\hline & & & & S. Enteritidis & $816.6)$ \\
\hline & & & & Other Salmonella & $31(64.6)$ \\
\hline & & & \multirow{3}{*}{$17(24.3)$} & S.Typhimurium & $1(5.8)$ \\
\hline \multirow[t]{3}{*}{2} & \multirow[t]{3}{*}{ Poultry organs } & \multirow[t]{3}{*}{70} & & S. Enteritidis & $2(11.7)$ \\
\hline & & & & Other Salmonella & $14(82.3)$ \\
\hline & & & \multirow{3}{*}{$21(35)$} & S.Typhimurium & $2(9.5)$ \\
\hline \multirow[t]{3}{*}{3} & \multirow[t]{3}{*}{ Poultry Meat } & \multirow[t]{3}{*}{60} & & S. Enteritidis & $1(4.7)$ \\
\hline & & & & Other Salmonella & $18(85.7)$ \\
\hline & & & \multirow{3}{*}{$9(15)$} & S.Typhimurium & $2(22.2)$ \\
\hline \multirow[t]{2}{*}{4} & \multirow[t]{2}{*}{ Poultry eggs } & \multirow[t]{2}{*}{60} & & S.Enteritidis & $1(11.1)$ \\
\hline & & & & Other Salmonella & $6(66.6)$ \\
\hline
\end{tabular}

\subsection{Antimicrobial Susceptibility Assay}

A high incidence of MDR was observed in all Salmonella isolates. Antimicrobial resistance pattern and MAR index of 95 Salmonella isolates were presented (Figure 1). All isolates were resistant against 11 antibiotics (oxacillin, clindamycin, erythromycin, streptomycin, nalidixic acid, fusidic acid, linezolid, rifampicin, tetracycline, minocycline, and vancomycin). Resistance to other antimicrobials was as follows: enrofloxacin, 95\%; gentamycin, 93\%; kanamycin, 91\%; sulphamethoxazole/trimethoprim, 91\%; ampicillin, $86 \%$; amoxicillin/clavulanic acid, $81 \%$; chloramphenicol, $81 \%$; cefixime, $76 \%$; ciprofloxacin, $19 \%$; imipenem, $12 \%$; cefepime, $9 \%$; meropenem, $2 \%$ (Figure 1). Isolates from associated poultry products (meat and eggs) were highly resistant to different antibiotics, which is a public health concern. A high MAR index (0.62-0.91) was observed in Salmonella. MAR index of different Salmonella serovars was as follows: S. Typhimurium ranged from 0.66 to 0.87 , S. Enteritidis ranged from 0.71-0.91, and in non-typeable Salmonella spp., it ranged from 0.62 to 0.91 . 


\begin{tabular}{|c|c|c|c|c|c|c|c|c|c|c|c|c|c|c|c|c|c|c|c|c|c|}
\hline $\begin{array}{c}\text { Is o late } \\
\text { No. }\end{array}$ & 䓂 & 产 & 产 & 灵 & 2 & 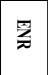 & $\cong$ & $\pi$ & 율 & 酉 & 0 & 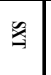 & $\begin{array}{l}\text { Sample } \\
\text { So ource }\end{array}$ & Serotype & 蛋 & 蛋 & 욜 & 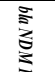 & $\frac{1}{2}$ & 竞 & $\begin{array}{l}\text { MAR R } \\
{ }_{* \mathbf{a} / \mathbf{b}}\end{array}$ \\
\hline $\begin{array}{l}\text { FML1 } \\
\text { FML2 }\end{array}$ & & & & & & & & & & & & & & $\begin{array}{l}\text { Salmo nella spp. } \\
\text { Salmo nella spp }\end{array}$ & & & & & & & $\begin{array}{l}0.8 \\
0.7\end{array}$ \\
\hline FML3 & & & & & & & & & & & & & & Salmonella spp. & & & & & & & 0.8 \\
\hline $\begin{array}{l}\text { FML 4 } \\
\end{array}$ & & - & 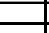 & ב & & - & Z & Z & E & - & & Z & & S.Enteritid is & & & & & & & 0.8 \\
\hline $\begin{array}{l}\text { FML5 } \\
\text { FML6 }\end{array}$ & - & & & 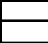 & & & & & 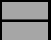 & & & 二 & & $\begin{array}{l}\text { Salmonella spp. } \\
\text { Salmonella spp. }\end{array}$ & & 二 & & & 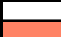 & - & $\begin{array}{l}0.7 \\
0.85\end{array}$ \\
\hline FML 7 & - & & & 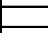 & & 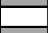 & & 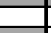 & 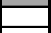 & & & & & Salmonella spp. & & & & & & & 0.75 \\
\hline $\begin{array}{l}\text { FML8 } \\
\text { FML9 }\end{array}$ & - & - & - & - & & - & 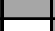 & 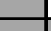 & 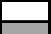 & E & & - & & $\begin{array}{l}\text { S.Typ himurium } \\
\text { Salmonella spp. }\end{array}$ & & & & & & & 0.85 \\
\hline FML 10 & & & & & & & & & & & & & & 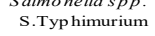 & & & & & & & $\begin{array}{l}0.85 \\
0.75\end{array}$ \\
\hline FML 11 & & & E & ב & & & & & & & & & & Salmo nella spp. & & 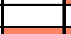 & & & - & & 0.62 \\
\hline \begin{tabular}{|l|l|l|} 
FML 12 \\
FML 13
\end{tabular} & & & - & - & & & & & - & - & & & & $\begin{array}{l}\text { almo nella spp. } \\
\text { Salmonella spp. }\end{array}$ & & 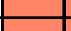 & - & & & - & 0.62 \\
\hline $\begin{array}{l}\text { FML } 14 \\
\text { FW 15 }\end{array}$ & 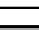 & ב & & & & - & & - & 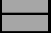 & 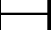 & - & - & & S.Typ himurium & & & & & & & $\begin{array}{l}0.79 \\
0.66\end{array}$ \\
\hline $\begin{array}{l}\text { FML } 15 \\
\text { FML16 }\end{array}$ & 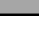 & - & -1 & 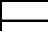 & & - & & - & Z & E & & & & $\begin{array}{l}\text { S.Typ himurum } \\
\text { Salmonella spp. }\end{array}$ & & E & & & & & 0.85 \\
\hline $\begin{array}{l}\text { FML } 17 \\
\text { FW }\end{array}$ & 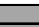 & ב & & - & & & - & E & ב & - & & 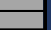 & & S.Enteritid is & & & & & & & $\begin{array}{l}0.73 \\
0.85\end{array}$ \\
\hline $\begin{array}{l}\text { FML } 18 \\
\text { FML } 19 \\
\end{array}$ & & & & & & & & & & & & & & $\begin{array}{l}\text { S.Enteritidis } \\
\text { Sal }\end{array}$ & & & & & & & 0.91 \\
\hline FML 20 & & & - & - & - & - & - & - & - & 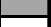 & & - & & $\begin{array}{l}\text { Salmo nella spp. } \\
\text { Salmonella spp. }\end{array}$ & & - & D & & & & 0.79 \\
\hline $\begin{array}{ll}\text { FML21 } \\
\end{array}$ & E & 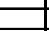 & & ב. & & & & & 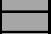 & - & & - & & salmonella spp. & & 工 & - & & & & $\begin{array}{l}0.79 \\
0.85\end{array}$ \\
\hline FML 22 & & & & & & & & & & & & & & Salmo nella spp. & & & & & & & 0.66 \\
\hline FML23 & - & $\ldots$ & - & 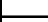 & - & - & - & - & - & & & - & & Salmo nella spp. & & -5 & & & & & 0.63 \\
\hline $\begin{array}{l}\text { FML 24 } \\
\text { FML 25 }\end{array}$ & 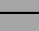 & - & & 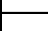 & & - & & & & & & & & $\begin{array}{l}\text { almone raspp. } \\
\text { S.Entitid is }\end{array}$ & & 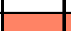 & & & & & $\begin{array}{l}0.87 \\
0.83\end{array}$ \\
\hline FML 26 & E & Z & - & Z & & Z & - & E & - & - & & - & & S.Enteritid is & & - & & & & & 0.83 \\
\hline FML 27 & & & & - & & & & & & & & & & Salmonella spp. & & & & & & & 0.83 \\
\hline $\begin{array}{l}\text { FML28 } \\
\text { FML 29 }\end{array}$ & - & - & - & -5 & & - & & - & - & - & & & & $\begin{array}{l}\text { S.Typhimurium } \\
\text { S. Typhimurium }\end{array}$ & & $-5+2>$ & & & & & $\begin{array}{l}0.83 \\
0.75\end{array}$ \\
\hline FML 30 & 二 & - & 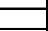 & ב. & - & Z & 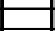 & - & - & ב & & - & & $\begin{array}{l}\text { Salmo nella spp. } \\
\text {. }\end{array}$ & & 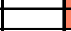 & E & & 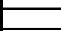 & & 0.75 \\
\hline FML31 & & - & & & & - & & & 二 & & & - & & Salmonella spp. & & $\square$ & 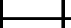 & & & & 0.75 \\
\hline $\begin{array}{l}\text { FML 32 } \\
\text { FML 33 }\end{array}$ & - & - & 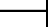 & 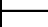 & - & 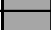 & - & - & - & 2 & 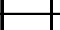 & - & & $\begin{array}{l}\text { S.Typhimurumium } \\
\text { S.Typhimurium }\end{array}$ & & 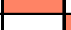 & 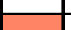 & & & & $\begin{array}{l}0.66 \\
0.71\end{array}$ \\
\hline $\begin{array}{l}\text { FML 34 } \\
\text { FML 35 }\end{array}$ & & ב & & & & ב & E & E & E & & & ב & & $\begin{array}{l}\text { S.Typhimurium } \\
\text { STlus }\end{array}$ & & ב & ב & & & & $\begin{array}{l}0.75 \\
0.75\end{array}$ \\
\hline FML36 & E & - & - & 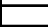 & 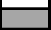 & - & - & - & 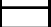 & 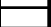 & & - & & $\begin{array}{l}\text { Salmo nella spp } \\
\text { Sp }\end{array}$ & & 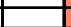 & & & & & 0.83 \\
\hline FML37 & & & & & & & & & & & & & & Salmo nella spp. & & & & & & & 0.91 \\
\hline FML 38 & - & - & 二 & $\bar{C}+2$ & & - & - & - & 二- & - & & 二 & & Salmo nella spp. & & $\overline{1}+3$ & & & 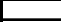 & & 0.91 \\
\hline $\begin{array}{l}\text { FML } 39 \\
\text { FML40 }\end{array}$ & - & - & 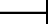 & - & & & & & & & & 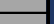 & & $\begin{array}{l}\text { S.Enteritid is } \\
\text { S }\end{array}$ & & & & & & & 0.83 \\
\hline $\begin{array}{l}\text { FML40 } \\
\text { FML41 }\end{array}$ & & - & - & - & & - & 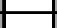 & 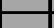 & - & & & - & & $\begin{array}{l}\text { Salmo nella spp. } \\
\text { Salmonella spp. }\end{array}$ & & - & & & & & $\begin{array}{l}0.83 \\
0.83\end{array}$ \\
\hline FML 42 & & - & - & - & & & & & & & & & & S.Enteritid is & & & & & & & $\begin{array}{l}0.83 \\
0.79\end{array}$ \\
\hline FML43 & - & - & - & - & & - & & & - & & & & & Salmonella spp. & & & & & & & 0.83 \\
\hline FML44 & & & $=$ & & & & & & & & & & & ritidi is & & & & & & & 0.87 \\
\hline FML45 & & & & & & & & 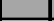 & & & & & & rella spp. & & & & & & & 0.83 \\
\hline FML46 & - & 二 & 二 & - & & - & & & - & & & - & & Salmo & & & & & & & 0.91 \\
\hline $\begin{array}{l}\text { FML47 } \\
\text { FML48 }\end{array}$ & & & & & & & & & - & & & - & & a & & & & & & & $\begin{array}{l}0.71 \\
0.91\end{array}$ \\
\hline PML 1 & - & ב & - & - & & - & - & - & - & - & & - & & Salmo nella spp. & & - & & & & & $\begin{array}{l}0.75 \\
0.75\end{array}$ \\
\hline PML 2 & - & - & - & - & & & - & & & & & & & S.Enteritid is & & & & & & & 0.79 \\
\hline PML4 & 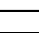 & - & 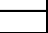 & & & - & & - & 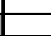 & & & - & & $\begin{array}{l}\text { Salmonella spp. } \\
\text { S.Typ himurium }\end{array}$ & & 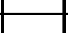 & 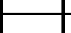 & & & & $\begin{array}{l}0.63 \\
0.71\end{array}$ \\
\hline PML5 & & & & & & & & & 二 & & & & & Salmo nella spp. & & & & & & & 0.83 \\
\hline PML6 & & - & - & $=$ & & - & - & Z & ב & - & & - & & S.Typ himurium & & 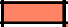 & - & & & & 0.79 \\
\hline $\begin{array}{l}\text { PML } 7 \\
\text { PML }\end{array}$ & - & - & - & -1 & & - & 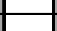 & - & - & $-5+2>$ & & - & & $\begin{array}{l}\text { S.Typ himurium } \\
\text { S Enteritidis is }\end{array}$ & & - & - & & & & $\begin{array}{l}0.79 \\
0.71\end{array}$ \\
\hline PML9 & 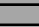 & 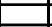 & & & & & & & & & & & & Salmo nella spp. & & & & & & & 0.66 \\
\hline PML 10 & & & - & - & & & & & & & & & & Salmonella spp. & & & & & & & 0.75 \\
\hline PML 11 & & & & - & & & & & & & & & & Salmo & & & & & & & 0.83 \\
\hline $\begin{array}{l}\text { PML12 } \\
\text { PML 13 }\end{array}$ & - & - & 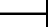 & & & - & & & - & & & & & $\begin{array}{l}\begin{array}{l}\text { almo } \\
\text { Salmo }\end{array} \\
\text { als }\end{array}$ & & & & & & & $\begin{array}{l}0.83 \\
0.87\end{array}$ \\
\hline PML 14 & & - & - & 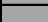 & & & & & 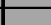 & & & 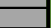 & & Salmo & & & & & & & $\begin{array}{l}0.87 \\
0.91\end{array}$ \\
\hline PML 15 & & & - & & & & & & - & & & & & & & & & & & & 0.83 \\
\hline PML 16 & & & 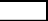 & & & & & & & & & & & & & & & & & & 0.83 \\
\hline PML 17 & - & - & - & $\ldots+$ & & - & - & - & C- & & & - & & Salmonella spp. & & & & & & & 0.83 \\
\hline $\begin{array}{l}\text { PML } 18 \\
\text { PML } 19\end{array}$ & - & - & - & - & & & - & & 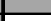 & & & & & Salm & & & & & & 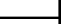 & 0.83 \\
\hline$\frac{P M L 1}{\text { PML2 }}$ & & & 7 & & & & & & 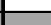 & & & & & Salme & & & & & & & $\begin{array}{l}0.79 \\
0.87\end{array}$ \\
\hline PML & 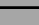 & - & 1 & - & & & & & 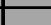 & & & & & $\begin{array}{l}\text { Salmo } \\
\text { Salma }\end{array}$ & & & & & & & $\begin{array}{l}0.83 \\
0.83\end{array}$ \\
\hline PML22 & & & & & & & & & & & & & & & & & & & & & 0.83 \\
\hline PML23 & & & & 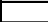 & & & & & & & & & & & & & & & & & 0.79 \\
\hline PML24 & & & & & & & & & & & & & & Salmo & & & & & & & 0.79 \\
\hline $\mathrm{PML}$ & & - & - & - & & & & & & & & - & & & & & & & & & 0.83 \\
\hline$\frac{P M 266}{P M L 27}$ & & -1 & $-5+2>$ & $-5+2>$ & & & & & & & & & & Salmo & & & & & & & $\begin{array}{l}0.83 \\
0.73\end{array}$ \\
\hline PML28 & - & $-5+2$ & 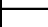 & - & & & 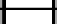 & -3 & - & & & 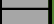 & & $\begin{array}{l}\text { S.Typhimurium } \\
\text { S. }\end{array}$ & & & & & 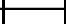 & & $\begin{array}{l}0.87 \\
0.87\end{array}$ \\
\hline PML 29 & & & & - & & & & & & & & & & & & & & & & & 0.83 \\
\hline $\begin{array}{l}\text { PML30 } \\
\end{array}$ & & & & - & & & & & & & & & & & & & & & & & 0.79 \\
\hline $\mathrm{OML}$ & & & & & & & & & & & & & & s. & & & & & & & \\
\hline $\mathrm{OML} 2$ & & & & - & & & & & 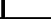 & & & & & Salmo nella a spp. & & & & & & & 0.79 \\
\hline OML & & & & - & & & & & & & & & & Salmo & & & & & & & 0.83 \\
\hline OML & & & & & & & & & & & & & & & & & & & & & 0.87 \\
\hline OML 6 & 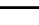 & 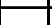 & & & & & & & 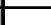 & & & & & & & & & & & & $\begin{array}{ll}0.02 \\
0.66\end{array}$ \\
\hline & & & & & & & & & & & & & & & & & & & & & \\
\hline & & & & & & & & & & & & & & & & & & & & & 0.71 \\
\hline $\mathrm{OM1}$ & & & & & & & & & & & & & & Salmo & & & & & & & 0.75 \\
\hline & & & & & & & & & & & & & & Salmo & & & & & & & 0.83 \\
\hline & & & & & & & & & {$[-5$} & & & & & $\begin{array}{l}\text { Salmo } \\
\text { S no }\end{array}$ & & & & & & & $\begin{array}{l}0.79 \\
0.91\end{array}$ \\
\hline OML 13 & & & & & & & & & & & & & & $\begin{array}{l}\text { Salmonella. } \\
\text { Salon }\end{array}$ & & & & & & 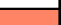 & $\begin{array}{l}0.83 \\
0.83\end{array}$ \\
\hline OML 14 & & & & 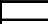 & & & - & & & & & ב & & Salmonella spp & & - & & & ב & ב & 0.79 \\
\hline $\begin{array}{l}\text { OML } 15 \\
\text { OML16 }\end{array}$ & & & & & & & & & & & & 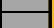 & & $\begin{array}{l}\text { Salmonella spp } \\
\text { Salmonella so }\end{array}$ & & & & & & 工 & $\begin{array}{l}0.83 \\
0.79\end{array}$ \\
\hline OML 17 & & & & & & & & & & & & 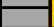 & & $\begin{array}{l}\text { Salmo nella sp } \\
\text { Salm. }\end{array}$ & & & & & & & $\begin{array}{l}0.83 \\
\end{array}$ \\
\hline
\end{tabular}

Figure 1. Salmonella strains (95) showing phenotypic antibiotic resistance profiles of 12 antibiotics, their source, origin, serotypes, and MAR index. Black squares indicate resistance; white squares indicate susceptibility; red squares indicate the presence of AMR genes; blue color presents isolates from poultry droppings, green; poultry food products (meat and

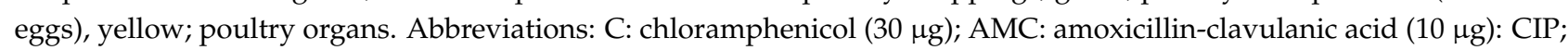
ciprofloxacin $(10 \mu \mathrm{g})$; CN: gentamicin $(10 \mu \mathrm{g})$; SXT: sulfamethoxazole/trimethoprim $(25 \mu \mathrm{g})$; K: kanamycin(30 $\mu \mathrm{g})$ : AMP: ampicillin $(30 \mu \mathrm{g})$; MEM: meropenem $(10 \mu \mathrm{g})$; IPM: imipenem $(10 \mu \mathrm{g})$; CEF: cefepime (30 $\mu \mathrm{g})$; CFM: cefixime (5 $\mu \mathrm{g})$; ENR: enrofloxacin $(10 \mathrm{ug})$; MAR: multiple antibiotic resistance; $\mathrm{a}^{*}$ : No. of antibiotics resistant; $\mathrm{b}^{*}$ : No. of antibiotics tested. 


\subsection{Distribution of Antibiotic Resistance and Virulence Genes in Salmonella Isolates}

The presence and absence of antibiotic resistance genes are presented in (Figure 1). The results showed that $S$. Enteritidis harbored resistance genes for cephalosporin and carbapenems resistance bla CMY-2 7/12 (58.3\%), bla TEM-1 8/12 (66.6\%), bla NDM-1 $0 / 12(0 \%)$, and ampC 0/12 (0\%); penicillin resistance genes bla PSE-1 1/12 (8.3\%) and bla OXA-1 1/12 (8.3\%); and the virulence gene of zoonotic importance sopE 12/12 (100\%). S. Typhimurium exhibited cephalosporins and carbapenems resistance genes blaCMY-2 6/14 (42.9\%), bla TEM-19/14 (64.3\%) bla NDM-1 0/14 (0\%), and ampC 1/14 (7.1\%); penicillin resistance genes bla PSE-23/14(21.4\%), bla OXA-1 0/14 (0\%), and sopE 13/14 (92.8\%). Other Salmonella spp. exhibited cephalosporins and carbapenems resistance genes bla CMY-2 28/69 (40.5\%), bla TEM-1, $40 / 69$ (57.9\%), bla NDM-1 0/69 (0\%), and ampC 7/69 (10.1\%); penicillin resistance genes bla PSE-1 6/69 (8.6\%), bla OXA-1 16/69 (23.1\%), and sopE 48/69 (69.5\%).

\subsection{Biofilm Formation Potential of Salmonella Isolates}

The Salmonella isolates' biofilm formation was significantly influenced by the source of isolation, serotype, and incubation temperature. Biofilm formation of Salmonella isolates from different sources at two temperatures $30^{\circ} \mathrm{C}$ and $37^{\circ} \mathrm{C}$ is presented (Figure 2). The results revealed that poultry food isolates (meat and eggs) exhibited strong biofilm production at both temperatures. Biofilm potential was assessed at $30^{\circ} \mathrm{C}$ and $37^{\circ} \mathrm{C}$ for $48 \mathrm{~h}$. Most of the Salmonella isolates of different origins showed strong biofilm at $37^{\circ} \mathrm{C}$ for $48 \mathrm{~h}$ (Table 4). The data showed that the number of $S$. Typhimurium $11 / 14(78.5 \%)$ with strong biofilm potential was almost double that of $S$. Enteritidis $5 / 12(41.7 \%)$ at $37^{\circ} \mathrm{C}$ for $48 \mathrm{~h}$.

Table 4. Biofilm potential of different Salmonella isolates at different temperatures.

\begin{tabular}{cccccc}
\hline Salmonella spp. & $\begin{array}{c}\text { Temperature } \\
\left({ }^{\circ} \mathbf{C}\right)\end{array}$ & $\begin{array}{c}\text { Weak } \\
\text { Biofilm }\end{array}$ & Moderate Biofilm & Strong Biofilm & No Biofilm \\
\hline S. Typhimurium & 30 & $3(21.4)$ & $4(28.5)$ & $7(50)$ & $0(0)$ \\
$(n=14)$ & 37 & $1(8)$ & $2(14.2)$ & $7(78.5)$ & $0(0)$ \\
S. Enteritidis & 30 & $2(16.6)$ & $5(48.3)$ & $3(25)$ & $0(0)$ \\
$(n=12)$ & 37 & $2(16.6)$ & $30(43.4)$ & $21(30.4)$ & $0(0)$ \\
Other Salmonella spp. & 30 & $18(26.1)$ & $20(28.9)$ & $38(55.1)$ & $0(0)$ \\
$(n=69)$ & 37 & $11(15.9)$ & & & $0(0)$ \\
\hline
\end{tabular}

3.5. Correlation between the Number of Isolates Resistant to Antibiotics and the Ability to Produce Biofilms at Different Temperatures

To determine correlation between biofilm formation and the number of MDR Salmonella, Spearman's rank correlation was used. All Salmonella isolates were biofilm producers at $30{ }^{\circ} \mathrm{C}$, and they exhibited MDR profiles. The Spearman's correlation coefficient $\left(r_{\mathrm{s}}\right)$ in this case was $0.591(p<0.001)$. Similarly, all MDR Salmonella produced biofilms at $37^{\circ} \mathrm{C}$. The Spearman's correlation coefficient $\left(r_{\mathrm{s}}\right)$ comparison was $0.423(p<0.001)$. We found a significant correlation between biofilm formation and the number of multidrug-resistant isolates at $30{ }^{\circ} \mathrm{C}(p=0.0001)$ and $37^{\circ} \mathrm{C}(p=0.00073)$. 

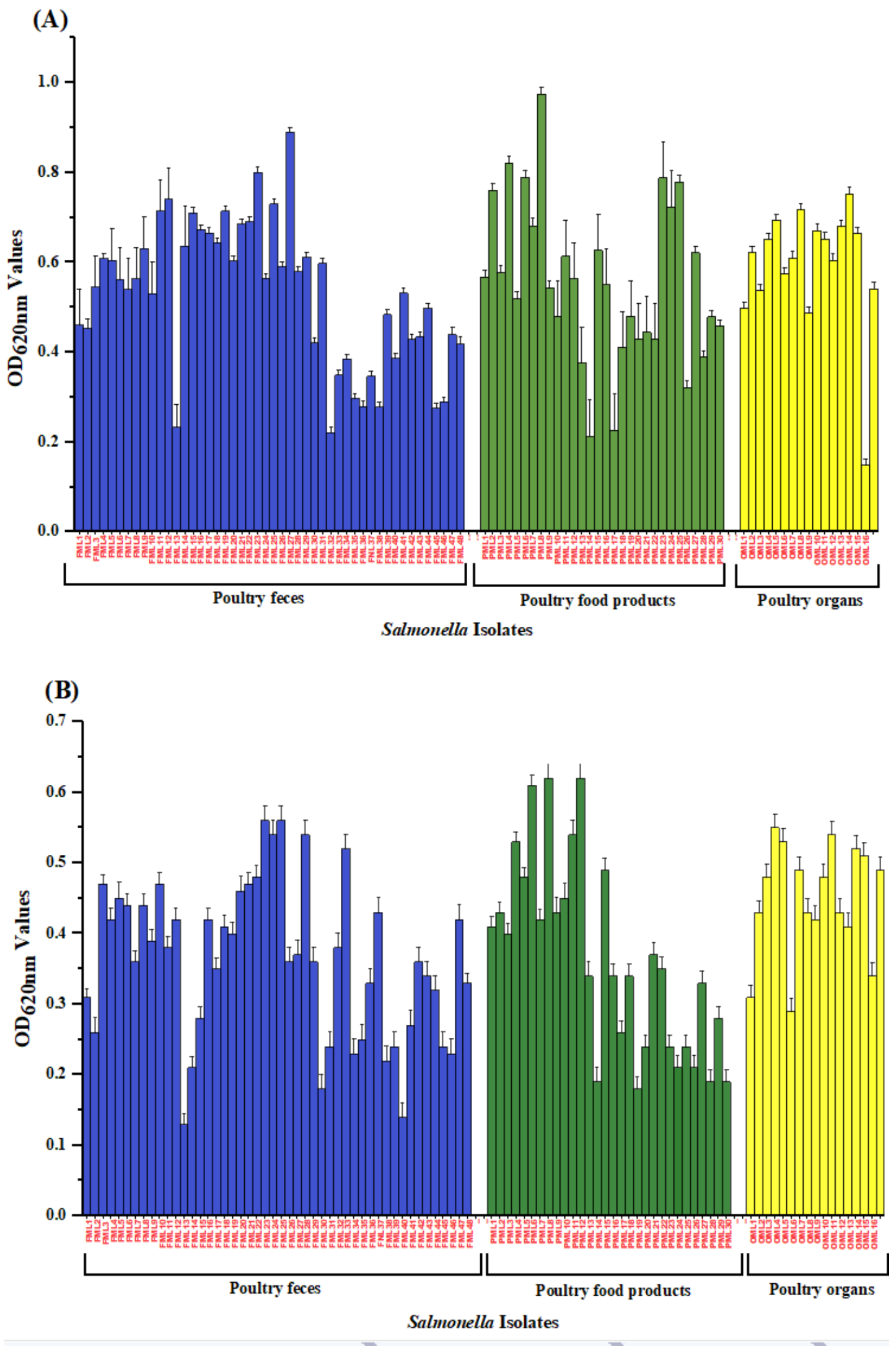

Figure 2. Results of biofilm formation assay. $X$-axis: Salmonella isolates from poultry droppings; poultry food products; poultry organs at two temperatures, (A): $37^{\circ} \mathrm{C} ;(\mathbf{B}): 30^{\circ} \mathrm{C}$ evaluated by crystal violet assay. Biofilm formation was assessed by staining the attached bacteria with $0.2 \% \mathrm{CV}$ and measuring the OD values at $620 \mathrm{~nm}$ after $48 \mathrm{~h}$ growth. Error bars represent standard deviations between three replicates. 


\subsection{Phenotypic Characterization of Extracellular Virulence Factors in Salmonella Isolates}

Phenotypic characterization of external virulence factors of Salmonella enterica obtained from poultry feces and associated poultry products were shown (Table 5). All Salmonella enterica 95/95 (100\%) in our study exhibited swarming and swimming motility. However, for $S$. Enteritidis isolates, 12/12 (100\%) showed hemolytic activity, 11/12 (91.6\%) displayed lipase activity, 12/12 (100\%) showed DNA degrading activity, and 10/12 (83\%) portrayed protease activity. For $S$. Typhimurium isolates, 13/14 (92.8\%) had hemolytic activity, $11 / 14(78.6 \%)$ showed lipase activity, 14/14 (100\%) displayed DNA degrading activity, 10/14 (83\%) portrayed protease activity. For non-typeable Salmonella isolates 67/69 (97.1\%) exhibited hemolytic activity, $67 / 69$ (97.1\%) DNA degrading activity, 66/69 (95.6\%) protease activity, and 65/69 (94.2\%) had lipase activity.

Table 5. Phenotypic virulence characteristics of Salmonella isolates.

\begin{tabular}{|c|c|c|c|c|c|c|}
\hline Salmonella spp. & $\begin{array}{c}\text { DNA Degrading } \\
\text { Activity }\end{array}$ & $\begin{array}{l}\text { Hemolytic } \\
\text { Activity }\end{array}$ & $\begin{array}{c}\text { Lipase } \\
\text { Activity }\end{array}$ & $\begin{array}{l}\text { Protease } \\
\text { Activity }\end{array}$ & $\begin{array}{l}\text { Swimming } \\
\text { Motility }\end{array}$ & $\begin{array}{l}\text { Swarming } \\
\text { Motility }\end{array}$ \\
\hline $\begin{array}{l}\text { S. Typhimurium } \\
(n=14)\end{array}$ & $14(100)$ & $13(92.8)$ & $11(78.6)$ & $10(83)$ & $14(100)$ & $14(100)$ \\
\hline $\begin{array}{l}\text { S. Enteritidis } \\
(n=12)\end{array}$ & $12(100)$ & $12(100)$ & $11(91.6)$ & $10(83)$ & $12(100)$ & $12(100)$ \\
\hline $\begin{array}{l}\text { Other } \\
\text { Salmonella spp. } \\
(n=69)\end{array}$ & $67(97.1)$ & $68(98.5)$ & $65(94.2)$ & $68(98.5)$ & $69(100)$ & 69 (100) \\
\hline
\end{tabular}

\section{Discussion}

Non-typhoidal Salmonella gastrointestinal infections have become a major public health concern. Consumption of undercooked/semi-cooked poultry products is a major source of Salmonella infection in humans [25]. Poultry and poultry food products (meat and eggs) are a cheap source of high-quality protein for human consumption [26].

In our study, the overall incidence of Salmonella was $26 \%$ from poultry droppings, organs, and poultry food product samples, which emphasizes the monitoring of NTS at poultry farms as well as retail markets in Pakistan. The incidence of Salmonella in this study was higher than a previous study from Pakistan (12\%), in other geographical regions, China $(20 \%)$, Trinidad, Spain (20.5\%), and Japan (7.9\%) [27]. However, it was lower compared to those detected in India (33.1\%), Canada (40\%), Oklahoma (41\%), Burkina Faso (55\%), and Myanmar (97.8\%) [20]. According to our study, we found non-typeable Salmonella spp. (73\%), Salmonella Typhimurium (15\%), and Salmonella Enteritidis (13\%). However, these results are similar to another study in Faisalabad, Punjab, where $S$. Typhimurium and $S$. Enteritidis prevalence was found $28.4 \%$ and $9.2 \%$, respectively [28]. A study from China revealed that Salmonella Enteritidis was the most abundant serovars, followed by $S$. Heidelberg and S. Typhimurium [19]. A similar study in Saudi Arabia showed the highest prevalence of $S$. Enteritidis (39.4\%), followed by $S$. Paratyphi (21.2\%), S. Typhimurium $(15.2 \%), S$. Typhi, and S. Arizona (12.1\%), respectively. These Salmonella isolates were isolated from environmental and clinical samples.

The emergence of antibiotic resistance in NTS is important for therapeutic control during the outbreak. 100\% resistance against 11 antibiotics (oxacillin, clindamycin, erythromycin, streptomycin, nalidixic acid, fusidic acid, linezolid, rifampicin, tetracycline, minocycline, and vancomycin) is alarming. This may be the result of the irrational use of antibiotics in poultry farming and the healthcare system. A previous study found Salmonella enterica was intrinsically resistant only to oxacillin [29], and in another, Salmonella from chicken meat and giblets in Egypt were 100\% resistant to erythromycin, penicillin, and amoxicillin. In comparison, $98.8 \%, 96.4 \%, 95.2 \%$, and $91.6 \%$ were resistant to nalidixic acid, sulphamethoxazole, oxytetracycline, and ampicillin [30]. According to another study, the highest resistance was found against erythromycin (100\%) and streptomycin (100\%) [31]. 
In the present study, we report resistance against enrofloxacin, gentamycin, kanamycin, sulphamethoxazole, trimethoprim, ampicillin, amoxicillin/clavulanic acid, chloramphenicol, and cefixime in the range of $76 \%$ to $96 \%$. This resistance pattern was similar to one of the previous studies where antimicrobial resistance to amoxicillin/clavulanic acid (96\%), kanamycin (88\%), ampicillin (85\%), and cephalothin (81\%) was observed [32]. In this study, we found phenotypic resistance against imipenem $(12 \%)$, cefixime $(76 \%)$, and cefepime $(9 \%)$. The emergence of resistance to carbapenems, third- and fourth-generation cephalosporin in NTS has not been reported previously from this region. Carbapenems are considered as only beta-lactam antibiotics that are considered effective against MDR pathogens [33]. The increasing spread of carbapenems, third- and fourth-generation cephalosporin resistance in NTS may spread to typhoidal Salmonella and other nosocomial enteric pathogens because they inhabit the same environment [34]. According to a previous study, a fourth-generation cephalosporin and fluoroquinolones resistant Salmonella typhi was reported in the Sindh region, Pakistan [35]. Another study from the Sindh region also revealed quinolones and cephalosporins resistance in NTS isolates from poultry meat [36]. Further, WGS analysis may reveal the source of such resistance in different Salmonella serovars [37]. Detection of MDR Salmonella isolates in this study warrant more attention towards surveillance of antibiotics usage in agriculture and human health care sectors in Pakistan. In our study, a high MAR index detection could be attributed to the increased use of clinically important antibiotics for bacterial infection control in humans and as therapeutic agents or growth promoters in veterinary practice for livestock in Pakistan. [38]. The high MAR observed in a similar study from Brazil ranged from 0.18-0.40 in different Salmonella serovars isolated from poultry sources [39]. MAR index of Salmonella isolates from seafood ranged from 0.14-0.45 in a study from Malaysia [40]. MAR index ranged from 0.21-0.46 in different Salmonella serovars isolated from ready-to-eat shrimps from a study in Nigeria [41]. A high number of tested antibiotics and high antibiotic resistance detection in our study compared to previous studies may be the cause of the high MAR index. The rapid emergence of antibiotic resistance is attributed to the selective pressure of antibiotics through evolutionary responses due to natural selection [42].

The emergence of extended-spectrum $\beta$-lactam/cephalosporin resistance in Salmonella can narrow its control options by antibiotics. Most of the antibiotic-resistant determinants are present in plasmids or integrons, which can transfer these genes to other bacterial species of different or the same group [43]. In the present study, among cephalosporin and carbapenems resistance genes in S. Typhimurium, bla TEM-1 (64.3\%) is more abundant than other genes. In S. Enteritidis, bla TEM-1 (66.6\%) was detected as the most prevalent. This is related to another study where bla TEM-1 (35.3\% and $72.7 \%)$ was detected as most prevalent in $S$. Typhimurium and $S$. Enteritidis isolates, respectively [28]. There are various reports in previous studies where the bla TEM-1 gene was detected as the most prevalent [44]. According to our study, the beta-lactamase penicillin gene bla PSE-1 gene (21.8\%) was most prevalent in S. Typhimurium. While in S. Enteritidis, bla PSE-1 (8.3\%) and bla OXA-1(8.3\%) were found in the same proportion. The mismatch between genotypic and phenotypic antibiotic resistance in our study may be due to mutation in genes and variation in gene expression within different Salmonella isolates. The sopE gene was found in all S. Enteritidis and $92.8 \%$ of $S$. Typhimurium, whereas in non-typeable Salmonella, it was observed in $68.1 \%$ isolates, which agrees with previous findings [45,46]. The sopE gene is encoded in SPI-1. It is identified in the isolates that are mainly involved in major epidemics; therefore, sopE has been identified as a major determinant in the spread of epidemic strains [47]. In another study, Salmonella Enteritidis isolated from chicken, eggs, and humans constitute the sopE gene, which may indicate its importance in zoonosis [48].

Biofilm formation may help in Salmonella survival in poultry farms and poultry food products [49]. In our study, S. Typhimurium (78.5\%) exhibits strong biofilm potential at $37^{\circ} \mathrm{C}$; similar results were revealed from previous studies [19,50]. Salmonella isolated from poultry food (meat and eggs) in our study with moderate to strong biofilm potential and having MDR characteristics is a concern for public health and poultry farming. Bacteria 
grown in biofilms have a greater ability to transfer genes horizontally than planktonic cells [51]. Biofilms increase the chances of gene transfer with the help of virulence factors and antibiotic-resistant genes from resistant to susceptible bacterial species, which leads to the emergence of new antibiotic resistance in pathogens [21]. The variation in the biofilm potential of the Salmonella isolates in this study may be due to the difference in incubation temperature $\left(30^{\circ} \mathrm{C}\right.$ and $\left.37^{\circ} \mathrm{C}\right)$ coupled with species diversity as described in a previous study [52]. The reason for choosing temperatures of $30^{\circ} \mathrm{C}$ and $37^{\circ} \mathrm{C}$ to assess biofilm formation potential was because sampling regions fall in the temperate zone, and summer temperatures are high. Most poultry meat and egg shops operate in warm climatic conditions where temperatures lie between $28^{\circ} \mathrm{C}$ to $30^{\circ} \mathrm{C}$. This study found a significant correlation between antibiotic resistance and biofilm formation at both temperatures $30^{\circ} \mathrm{C}$ and $37^{\circ} \mathrm{C}$. Such a relationship has been described for other bacteria, although the findings were sometimes inconsistent, and the correlations were speciesdependent [53]. Our data showed that the Salmonella serovars from poultry gut, organs, and food (meat and egg) had virulence characteristics and determined the pathogenicity of Salmonella isolates. These external virulence factors are swimming and swarming motility, hemolysis, lipase, the presence of protease, and DNA degrading activity. Motility is an important pathogenic property of bacteria that is closely related to virulence factor production, antibiotic resistance, and biofilm potential [54]. According to a previous study, a significant linkage between protease production, motility, and pathogenesis has been reported [55]. Extracellular protease, DNA structure, and lipolytic activity positively correlated with biofilm formation [56-58].

Management strategies for antibiotic resistance should be adopted to control the dissemination of antibiotic resistance includes the following: improved information to enhance the awareness, control of non-therapeutic use of antibiotics in food animal production system, improvement in diagnostic procedures, and enhancement of microbiological laboratory equipment and personals $[59,60]$. These suggestions may assist in the reduction of antibiotic resistance and can improve the public health sector in Pakistan.

\section{Conclusions}

These findings indicated highly antibiotic-resistant NTS serovars with zoonotic potential at local poultry farms in Pakistan, emphasizing the need to adopt more biosecurity measures, environmental and personal hygiene awareness among the local poultry farmers. The detection of the most important foodborne zoonotic Salmonella enterica serovars Typhimurium and Enteritidis is of public health significance. The emergence of MDR Salmonella serovars is of great concern for the targeted antimicrobial therapy. Resistance from these Salmonella isolates may transfer to typhoidal Salmonella and other Enterobacteriaceae family as these pathogens share a common environment for propagation. Irrational usage of different antibiotics in the poultry industry should be checked to avoid spreading and disseminating antibiotic resistance. The biofilm formation potential of these isolates is of great concern for the food industry and public health.

Author Contributions: A.S.: Performed experiments and wrote the manuscript. S.A. (Sara Azim): Performed experiments. S.A. (Saadia Andleeb) and M.I.: Data analysis and technical assistance, A.A. (Aitezaz Ahsan): Data collection from different regions of Pakistan and technical assistance. A.A. (Amjad Ali) and A.R.: Planned and executed experiments, analyzed data, and wrote the manuscript. All authors have read and agreed to the published version of the manuscript.

Funding: This study was financially supported through an ICT Endowment scholarship from the National University of Science and Technology, Islamabad, Pakistan.

Acknowledgments: The authors acknowledge Mudassar Mohiuddin for valuable comments and suggestions.

Conflicts of Interest: All authors declare no competing interests. 


\section{References}

1. Gharieb, R.; Tartor, Y.H.; Khedr, M.H.E. Non-Typhoidal Salmonella in poultry meat and diarrhoeic patients: Prevalence, antibiogram, virulotyping, molecular detection and sequencing of class I integrons in multidrug resistant strains. Gut Pathog. 2015, 7, 1-11. [CrossRef]

2. Guibourdenche, M.; Roggentin, P.; Mikoleit, M.; Fields, P.I.; Bockemühl, J.; Grimont, P.; Weill, F.-X. Supplement $2003-2007$ (No. 47) to the White-Kauffmann-Le Minor scheme. Res. Microbiol. 2010, 161, 26-29. [CrossRef]

3. Jajere, S.M. A review of Salmonella enterica with particular focus on the pathogenicity and virulence factors, host specificity and antimicrobial resistance including multidrug resistance. Veter. World 2019, 12, 504-521. [CrossRef]

4. Majowicz, S.; Musto, J.; Scallan, E.; Angulo, F.; Kirk, M.; O’Brien, S.; Jones, T.F.; Fazil, A.; Hoekstra, R.M.; International Collaboration on Enteric Disease "Burden of Illness" Studies. The global burden of nontyphoidal Salmonella gastroenteritis. Clin. Infect. Dis. 2010, 50, 882-889. [CrossRef]

5. Mouttotou, N.; Ahmad, S.; Kamran, Z.; Koutoulis, K.C. Prevalence, Risks and Antibiotic Resistance of Salmonella in Poultry Production Chain. Curr. Top. Salmonella Salmonellosis 2017, 2017, 134-215. [CrossRef]

6. Heredia, N.; García, S. Animals as sources of food-borne pathogens: A review. Anim. Nutr. 2018, 4, 250-255. [CrossRef] [PubMed]

7. Thai, T.H.; Hirai, T.; Lan, N.T.; Yamaguchi, R. Antibiotic resistance profiles of Salmonella serovars isolated from retail pork and chicken meat in North Vietnam. Int. J. Food Microbiol. 2012, 156, 147-151. [CrossRef]

8. Nair, D.V.T.; Venkitanarayanan, K.; Kollanoor, J.A. Antibiotic-resistant Salmonella in the food supply and the potential role of antibiotic alternatives for control. Foods 2018, 7, 167. [CrossRef]

9. Lai, J.; Wu, C.; Wu, C.; Qi, J.; Wang, Y.; Wang, H.; Liu, Y.; Shen, J. Serotype distribution and antibiotic resistance of Salmonella in food-producing animals in Shandong province of China, 2009 and 2012. Int. J. Food Microbiol. 2014, 180, 30-38. [CrossRef] [PubMed]

10. Clothier, K.A.; Kim, P.; Mete, A.; Hill, A.E. Frequency, serotype distribution, and antimicrobial susceptibility patterns of Salmonella in small poultry flocks in California. J. Veter. Diagn. Investig. 2018, 30, 471-475. [CrossRef] [PubMed]

11. Iwamoto, M.; Reynolds, J.; Karp, B.; Tate, H.; Cray, P.; Plumblee, J.R.; Hoekstra, R.M.; Whichard, J.M.; Mahon, B.E. CeftriaxoneResistant Nontyphoidal Salmonella from Humans, Retail Meats, and Food Animals in the United States, 1996-2013. Foodborne Pathog. Dis. 2017, 14, 74-83. [CrossRef] [PubMed]

12. Yang, X.; Huang, J.; Wu, Q.; Zhang, J.; Liu, S.; Guo, W.; Cai, S.; Yu, S. Prevalence, antimicrobial resistance and genetic diversity of Salmonella isolated from retail ready-to-eat foods in China. Food Control. 2016, 60, 50-56. [CrossRef]

13. Antunes, P.; Mourão, J.; Campos, J.; Peixe, L. Salmonellosis: The role of poultry meat. Clin. Microbiol. Infect. 2016, $22,110-121$. [CrossRef]

14. Nakatsuchi, A.; Inagaki, M.; Sugiyama, M.; Usui, M.; Asai, T. Association of Salmonella Serotypes with Quinolone Resistance in Broilers. Food Saf. 2018, 6, 156-159. [CrossRef]

15. Nde, C.W.; Fakhr, M.K.; Doetkott, C.; Logue, C.M. An evaluation of conventional culture, invA PCR, and the real-time PCR iQ-Check kit as detection tools for Salmonella in naturally contaminated premarket and retail turkey. J. Food Prot. 2008, 71, 386-391. [CrossRef]

16. Gunasegaran, T.; Rathinam, X.; Kasi, M.; Sathasivam, K.; Sreenivasan, S.; Subramaniam, S. Isolation and identification of Salmonella from curry samples and its sensitivity to commercial antibiotics and aqueous extracts of Camelia sinensis (L.) and Trachyspermum ammi (L.). Asian Pac. J. Trop. Biomed. 2011, 1, 266-269. [CrossRef]

17. Soumet, C.; Ermel, G.; Rose, V.; Rose, N.; Drouin, P.; Salvat, G.; Colin, P. Identification by a multiplex PCR-based assay ofSalmonellaTyphimurium andSalmonellaEnteritidis strains from environmental swabs of poultry houses. Lett. Appl. Microbiol. 1999, 29, 1-6. [CrossRef] [PubMed]

18. Moe, A.Z.; Paulsen, P.; Pichpol, D.; Fries, R.; Irsigler, H.; Baumann, M.P.O.; Oo, K.N. Prevalence and Antimicrobial Resistance of Salmonella Isolates from Chicken Carcasses in Retail Markets in Yangon, Myanmar. J. Food Prot. 2017, 80, 947-951. [CrossRef] [PubMed]

19. Lamas, A.; Miranda, J.; Vazquez, B.; Cepeda, A.; Franco, C. Biofilm formation, phenotypic production of cellulose and gene expression in Salmonella enterica decrease under anaerobic conditions. Int. J. Food Microbiol. 2016, 238, 63-67. [CrossRef]

20. Marangoni, F.; Corsello, G.; Cricelli, C.; Ferrara, N.; Ghiselli, A.; Lucchin, L.; Poli, A. Role of poultry meat in a balanced diet aimed at maintaining health and wellbeing: An Italian consensus document. Food Nutr. Res. 2015, 59, 27606. [CrossRef]

21. Galloway, W.R.; Hodgkinson, J.; Bowden, S.; Welch, M.; Spring, D.R. Applications of small molecule activators and inhibitors of quorum sensing in Gram-negative bacteria. Trends Microbiol. 2012, 20, 449-458. [CrossRef]

22. Odoch, T.; Sekse, C.; L'Abee-Lund, T.M.; Hansen, H.C.H.; Kankya, C.; Wasteson, Y. Diversity and Antimicrobial Resistance Genotypes in Non-Typhoidal Salmonella Isolates from Poultry Farms in Uganda. Int. J. Environ. Res. Public Health 2018, 15, 324. [CrossRef] [PubMed]

23. Babapour, E.; Haddadi, A.; Mirnejad, R.; Angaji, S.A.; Amirmozafari, N. Biofilm formation in clinical isolates of nosocomial Acinetobacter baumannii and its relationship with multidrug resistance. Asian Pac. J. Trop. Biomed. 2016, 6, 528-533. [CrossRef]

24. Stepanović, S.; Vukovic, D.; Dakić, I.; Savić, B.; Švabić-Vlahović, M. A modified microtiter-plate test for quantification of staphylococcal biofilm formation. J. Microbiol. Methods 2000, 40, 175-179. [CrossRef] 
25. Eguale, T.; Gebreyes, W.A.; Asrat, D.; Alemayehu, H.; Gunn, J.S.; Engidawork, E. Non-typhoidal Salmonella serotypes, antimicrobial resistance and co-infection with parasites among patients with diarrhea and other gastrointestinal complaints in Addis Ababa, Ethiopia. BMC Infect. Dis. 2015, 15, 497. [CrossRef] [PubMed]

26. Kumar, M.; Dahiya, S.P.; Ratwan, P. Backyard poultry farming in India: A tool for nutritional security and women empowerment. Biol. Rhythm. Res. 2019. [CrossRef]

27. Michael, G.; Schwarz, S. Antimicrobial resistance in zoonotic nontyphoidal Salmonella: An alarming trend? Clin. Microbiol. Infect. 2016, 22, 968-974. [CrossRef] [PubMed]

28. Duc, V.M.; Nakamoto, Y.; Fujiwara, A.; Toyofuku, H.; Obi, T.; Chuma, T. Prevalence of Salmonella in broiler chickens in Kagoshima, Japan in 2009 to 2012 and the relationship between serovars changing and antimicrobial resistance. BMC Veter. Res. 2019, 15, 108. [CrossRef] [PubMed]

29. Wajid, M.; Awan, A.B.; Saleemi, M.K.; Weinreich, J.; Schierack, P.; Sarwar, Y.; Ali, A. Multiple Drug Resistance and Virulence Profiling ofSalmonella entericaSerovars Typhimurium and Enteritidis from Poultry Farms of Faisalabad, Pakistan. Microb. Drug Resist. 2019, 25, 133-142. [CrossRef]

30. Li, B.; Liu, C.; Liu, L.; Li, S.; Fan, N.; Hou, H.; Jin, J.; Xing, Y. [Prevalence and etiologic agent of Salmonella in livestock and poultry meats in Huai'an City during 2015-2016]. Wei Sheng Yan Jiu J. Hyg. Res. 2018, 47, 260-300.

31. Stock, I.; Wiedemann, B. Natural antibiotic susceptibility of Salmonella enterica strains. Int. J. Antimicrob. Agents 2000, 16, 211-217. [CrossRef]

32. Abd-Elghany, S.; Sallam, K.; Abd-Elkhalek, A.; Tamura, T. Occurrence, genetic characterization and antimicrobial resistance of Salmonella isolated from chicken meat and giblets. Epidem. Infect. 2015, 143, 997-1003. [CrossRef] [PubMed]

33. El-Tayeb, M.A.; Ibrahim, A.S.; Al-Salamah, A.A.; Almaary, K.S.; Elbadawi, Y.B. Prevalence, serotyping and antimicrobials resistance mechanism of Salmonella enterica isolated from clinical and environmental samples in Saudi Arabia. Braz. J. Microbiol. 2017, 48, 499-508. [CrossRef]

34. Gad, A.H.; Abo-Shama, U.H.; Harclerode, K.K.; Fakhr, M.K. Prevalence, Serotyping, Molecular Typing, and Antimicrobial Resistance of Salmonella Isolated From Conventional and Organic Retail Ground Poultry. Front. Microbiol. 2018, 9, 2653. [CrossRef] [PubMed]

35. Temkin, E.; Adler, A.; Lerner, A.; Carmeli, Y. Carbapenem-resistant Enterobacteriaceae: Biology, epidemiology, and management. Ann. N. Y. Acad. Sci. 2014, 1323, 22-42. [CrossRef] [PubMed]

36. Fernandez, J.; Guerra, B.; Rodicio, M.R. Resistance to Carbapenems in Non-Typhoidal Salmonella enterica Serovars from Humans, Animals and Food. Veter. Sci. 2018, 5, 40. [CrossRef] [PubMed]

37. Klemm, E.J.; Shakoor, S.; Page, A.J.; Qamar, F.N.; Judge, K.; Saeed, D.K.; Wong, V.K.; Dallman, T.J.; Nair, S.; Baker, S.; et al. Emergence of an Extensively Drug-Resistant Salmonella enterica Serovar Typhi Clone Harboring a Promiscuous Plasmid Encoding Resistance to Fluoroquinolones and Third-Generation Cephalosporins. mBio 2018, 9. [CrossRef]

38. Soomro, A.H.; Khaskheli, M.; Bhutto, M.B.; Shah, G.; Memon, A.; Dewani, P. Prevalence and antimicrobial resistance of Salmonella serovars isolated from poultry meat in Hyderabad, Pakistan. Turk. J. Veter. Anim. Sci. 2011, 34, 455-460.

39. Borges, K.A.; Furian, T.Q.; Souza SNd Salle, C.T.P.; Moraes, H.L.d.S.; Nascimento, V.P.D. Antimicrobial resistance and molecular characterization of Salmonella enterica serotypes isolated from poultry sources in Brazil. Braz. J. Poult. Sci. 2019, 21. [CrossRef]

40. Budiati, T.; Rusul, G.; Wan-Abdullah, W.N.; Arip, Y.M.; Ahmad, R.; Thong, K.L.J.A. Prevalence, antibiotic resistance and plasmid profiling of Salmonella in catfish (Clarias gariepinus) and tilapia (Tilapia mossambica) obtained from wet markets and ponds in Malaysia. Aquaculture 2013, 372, 127-132. [CrossRef]

41. Beshiru, A.; Igbinosa, I.H.; Igbinosa, E.O. Prevalence of antimicrobial resistance and virulence gene elements of Salmonella serovars from ready-to-eat (RTE) shrimps. Front. Microbiol. 2019, 10, 1613. [CrossRef]

42. Deekshit, V.K.; Kumar, B.K.; Rai, P.; Rohit, A.; Karunasagar, I. Simultaneous detection of Salmonella pathogenicity island 2 and its antibiotic resistance genes from seafood. J. Microbiol. Methods 2013, 93, 233-238. [CrossRef]

43. Biffi, C.P.; Stefani, L.M.; Miletti, L.C.; Matiello, C.A.; Backes, R.G.; Almeida, J.M.; Neves, G.B. Phenotypic and genotypic resistance profile of Salmonella Typhimurium to antimicrobials commonly used in poultry. Braz. J. Poult. Sci. 2014, 16, 93-96. [CrossRef]

44. Zhao, X.; Yang, J.; Zhang, B.; Sun, S.; Chang, W. Characterization of Integrons and Resistance Genes in Salmonella Isolates from Farm Animals in Shandong Province, China. Front. Microbiol. 2017, 8, 1300. [CrossRef]

45. Borges, K.A.; Furian, T.Q.; Borsoi, A.; Moraes, H.L.; Salle, C.T.P.; Nascimento, V.P.D. Detection of virulence-associated genes in Salmonella Enteritidis isolates from chicken in South of Brazil. Pesquisa Veterinária Brasileira 2013, 33, 1416-1422. [CrossRef]

46. El-Sharkawy, H.; Tahoun, A.; El-Gohary, A.E.; El-Abasy, M.; El-Khayat, F.; Gillespie, T.; Kitade, Y.; Hafez, H.M.; Neubauer, H.; El-Adawy, H. Epidemiological, molecular characterization and antibiotic resistance of Salmonella enterica serovars isolated from chicken farms in Egypt. Gut Pathogens. 2017, 9, 8. [CrossRef] [PubMed]

47. Hopkins, K.L.; Threlfall, E.J. Frequency and polymorphism of sopE in isolates of Salmonella enterica belonging to the ten most prevalent serotypes in England and Wales. J. Med. Microbiol. 2004, 53, 539-543. [CrossRef]

48. Han, J.; Gokulan, K.; Barnette, D.; Khare, S.; Rooney, A.W.; Deck, J.; Nayak, R.; Stefanova, R.; Hart, M.E.; Foley, S.L. Evaluation of Virulence and Antimicrobial Resistance inSalmonella entericaSerovar Enteritidis Isolates from Humans and Chicken- and Egg-Associated Sources. Foodborne Pathog. Dis. 2013, 10, 1008-1015. [CrossRef] [PubMed] 
49. Latasa, C.; Roux, A.; Toledo-Arana, A.; Ghigo, J.M.; Gamazo, C.; Penadés, J.R.; Lasa, I. BapA, a large secreted protein required for biofilm formation and host colonization of Salmonella enterica serovar Enteritidis. Mol. Microbiol. 2005, 58, 1322-1339. [CrossRef] [PubMed]

50. de Oliveira, T.L.C.; de Araújo Soares, R.; Piccoli, R.H. A Weibull model to describe antimicrobial kinetics of oregano and lemongrass essential oils against Salmonella Enteritidis in ground beef during refrigerated storage. Meat Sci. 2013, 93, 645-651. [CrossRef]

51. Borges, A.; Abreu, A.C.; Dias, C.; Saavedra, M.J.; Borges, F.; Simões, M. New Perspectives on the Use of Phytochemicals as an Emergent Strategy to Control Bacterial Infections Including Biofilms. Molecules 2016, 21, 877. [CrossRef]

52. Jensen, M.B.F.; Schjørring, S.; Björkman, J.T.; Torpdahl, M.; Litrup, E.; Nielsen, E.M.; Niskanen, T. External quality assessment for molecular typing of Salmonella 2013-2015: Performance of the European national public health reference laboratories. Eur. J. Clin. Microbiol. Infect. Dis. 2017, 36, 1923-1932. [CrossRef]

53. Troxell, B.; Petri, N.; Daron, C.; Pereira, R.; Mendoza, M.; Hassan, H.M.; Koci, M.D. Poultry Body Temperature Contributes to Invasion Control through Reduced Expression of Salmonella Pathogenicity Island 1 Genes in Salmonella enterica Serovars Typhimurium and Enteritidis. Appl. Environ. Microbiol. 2015, 81, 8192-8201. [CrossRef]

54. Runkel, S.; Wells, H.C.; Rowley, G. Living with stress: A lesson from the enteric pathogen Salmonella enterica. In Advances in Applied Microbiology; Elsevier: Amsterdam, The Netherlands, 2013; Volume 83, pp. 87-144.

55. Simm, R.; Ahmad, I.; Rhen, M.; Le Guyon, S.; Römling, U. Regulation of biofilm formation in Salmonella enterica serovar Typhimurium. Future Microbiol. 2014, 9, 1261-1282. [CrossRef] [PubMed]

56. Baugh, S.; Ekanayaka, A.S.; Piddock, L.J.V.; Webber, M.A. Loss of or inhibition of all multidrug resistance efflux pumps of Salmonella enterica serovar Typhimurium results in impaired ability to form a biofilm. J. Antimicrob. Chemother. 2012, 67, 2409-2417. [CrossRef] [PubMed]

57. Frees, D.; Brøndsted, L.; Ingmer, H. Bacterial proteases and virulence. In Regulated Proteolysis in Microorganisms; Springer: Berlin/Heidelberg, Germany, 2013; pp. 161-192.

58. Rosenau, F.; Isenhardt, S.; Gdynia, A.; Tielker, D.; Schmidt, E.; Tielen, P.; Schobert, M.; Jahn, D.; Wilhelm, S.; Jaeger, K.-E. Lipase LipC affects motility, biofilm formation and rhamnolipid production in Pseudomonas aeruginosa. FEMS Microbiol. Lett. 2010, 309, 25-34. [CrossRef] [PubMed]

59. Ganguly, N.K.; Wattal, C.; Chandy, S.J.; Arora, S.K.; Gupta, U.; Kotwani, A. Situation Analysis Antibiotic Use and Resistance in India; Public Health Foundation of India, and Center for Disease Dynamics, Economics and Policy: New Delhi, India, 2011.

60. Pruden, A.; Larsson, D.J.; Amézquita, A.; Collignon, P.; Brandt, K.K.; Graham, D.W.; Lazorchak, J.M.; Suzuki, S.; Silley, P.; Snape, J.R.; et al. Management Options for Reducing the Release of Antibiotics and Antibiotic Resistance Genes to the Environment. Environ. Health Perspect. 2013, 121, 878-885. [CrossRef] 